\title{
Chronic aftershocks of an earthquake on the well-being of children in Haiti: violence, psychosocial health and slavery
}

\author{
Jhumka Gupta ScD MPH, Alpna Agrawal PhD MPH
}

Previously published at www.cmaj.ca

$\mathrm{B}$ efore the Jan. 12, 2010, earthquake in Haiti, chronic poverty, lack of infrastructure and poor performance on key health indicators had long threatened the well-being of Haiti's children. Though Haiti ratified the United Nations (UN) Convention on the Rights of the Child in $1994,{ }^{1}$ this nation has the highest mortality rates among infants, children less than five years of age and mothers in the Western hemisphere. ${ }^{2}$ Only $50 \%$ of primary school-aged children are enrolled in school, and less than $2 \%$ complete secondary school. ${ }^{2}$ Adult life expectancy is a mere 61 years, and the national HIV prevalence is $2.2 \%{ }^{2}$

Since the earthquake, the well-being and safety of children, who comprise $37.5 \%$ of Haiti's population, totalling 3453709 children, ${ }^{3}$ have become a focal point of global attention. The threat of child trafficking has been underscored as a particularly imminent health and safety issue in this postdisaster setting. Child trafficking is not a new issue in Haiti. It often occurs within the context of other health and safety concerns, such as poverty, gender-based violence against women and household health, including the health of children's caregivers. In this analysis, we describe the extent of the health and safety risks faced by Haiti's most vulnerable children before the earthquake, highlight how such risks may now be exacerbated and suggest how the risks may be addressed in the future.

\section{Children at risk}

We used the results of the Haitian demographic health survey Enquête Mortalité, Morbidité et Utilisation des Services that collected nationally representative data from September 2005 to June 2006. We analyzed data from 7773 surveyed households, where 22495 children resided. ${ }^{4}$ We found that $32.5 \%$ of households with children met the UNICEF definition of orphaned and vulnerable children ${ }^{5}$ and that $5.2 \%$ of adult heads of households with children admitted to harbouring a restavèk (Haitian Creole for "stay with"). The UN considers restavèks to be victims of modern-day child slavery. ${ }^{6}$ Rich families were more likely to have restavèks ( $p \leq 0.05$ ); about $69 \%$ of restavèks worked in rich households, compared with $16 \%$ who worked in poor households. Restavèks were more likely to be girls than boys $(p \leq 0.05)$; almost $77 \%$ of restavèks were girls, and $23 \%$ were boys. Restavèks are often the result of impoverished Haitian parents turning their children over to wealthier families with the hope that the children

\section{Key points}

- Child trafficking has emerged as a major concern following Haiti's 2010 earthquake.

- In 2005/06, 32.5\% of Haitian households with children included orphans and vulnerable children.

- Before Haiti's 2010 earthquake, orphaned and vulnerable children faced health threats related to household violence against intimate partners and caregiver HIV.

- Postdisaster conditions will likely exacerbate family violence and worsen the health of caregivers.

- Rebuilding efforts should include strategies to reduce violence against women and ensure HIV treatment for caregivers.

would perform household labour in exchange for food, shelter and schooling. ${ }^{6}$ Unfortunately, the restavè system often results in exploitative situations; research shows that restavèks, especially young girls, are subjected to high rates of physical and sexual abuse. ${ }^{6}$

Among orphaned and vulnerable children, $51.4 \%$ of girls and $48.6 \%$ of boys lived in a household where they were exposed to male-perpetrated physical or sexual violence against female intimate partners in the year preceding the survey (Figure 1). ${ }^{4}$ Moreover, orphaned and vulnerable children were more likely to live with an HIV-infected adult than nonorphaned and vulnerable children $(p \leq 0.05)$ and, of orphaned and vulnerable children, girls were more likely than boys to be in this situation $(p \leq 0.05)$ after accounting for age, urban or rural residence, and household standard of living.

Our findings must be considered in the context of several important limitations, including potential underreporting by adults regarding all orphaned and vulnerable children residing in their households, lack of information on these children's health status, and self-reported experiences with violence against intimate partners. However, several critical implications can be drawn about the health and safety of children included in these analyses. These data ${ }^{4}$ suggest that Haiti's most vulnerable children were exposed to psychosocial stres-

From the Yale School of Public Health and Center for Interdisciplinary Research on AIDS, Yale University, New Haven, USA

CMAJ 2010. DOI:10.1503/cmaj.100526 


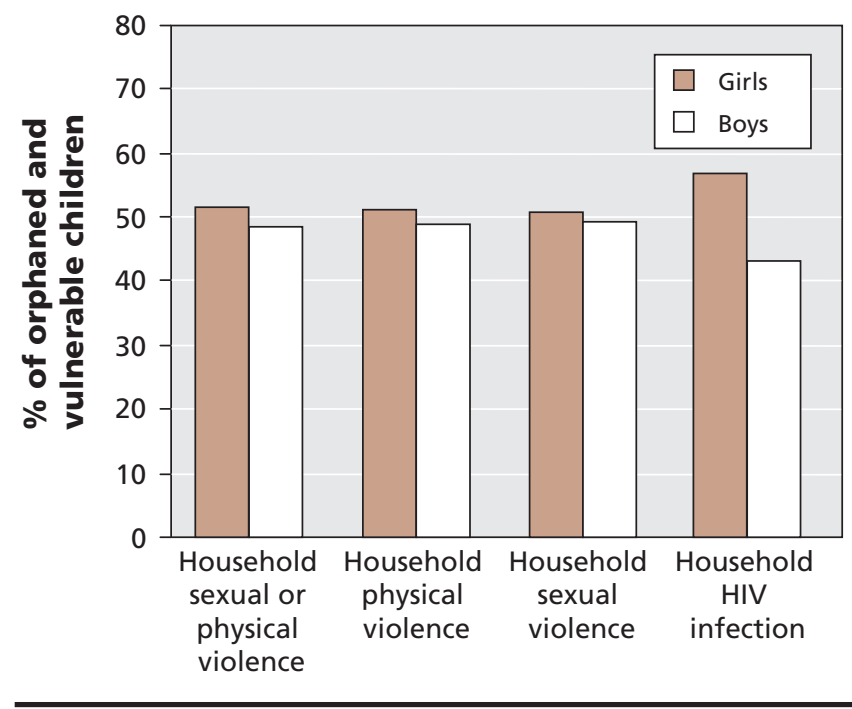

Figure 1: Proportion of orphaned and vulnerable children in Haiti who lived in households where men committed physical or sexual violence against intimate female partners and in households with HIV-infected adults, by gender. ${ }^{4}$ Note: Statistical analyses were performed with Stata 10.0 to appropriately account for the survey's complex sampling design and differential weighting at the household level.

sors and adversity, such as gender-based violence and HIVpositive caregivers, long before the earthquake.

Many studies have shown that witnessing violence against intimate partners or living in a household where violence occurs has been linked to a host of negative consequences for child health, including depression, suicidal tendencies, trauma and anxiety. ${ }^{7}$ Of critical importance, recent work has documented that such children are more likely to suffer from two leading causes of child mortality: acute respiratory illnesses and diarrheal diseases, even after accounting for environmental and socio-economic factors. ${ }^{8}$ These children may also be at particular risk of experiencing violence and physical injuries themselves ${ }^{7}$ it has been well-documented that violence against children is likely to occur in households where violence against intimate partners takes place., ${ }^{9,10}$

Our findings suggest that orphaned and vulnerable children in general, and orphaned and vulnerable girls in particular, are at potentially greater risk of experiencing the adverse consequences of living in a household with an HIV-infected adult. Such adverse consequences include being more vulnerable to poor psychosocial and developmental outcomes, food insecurity and incomplete schooling. ${ }^{11}$

\section{After the earthquake}

The earthquake's aftermath may introduce unique and additional adversity to the lives of children who are already vulnerable. Gender-based violence against children and women can heighten in postdisaster settings. ${ }^{12,13}$ Specifically, lack of public order, population displacement and increased economic insecurity may increase the likelihood of violence against vulnerable children and women. For instance, in rural Haiti, where residents tend to be poorer, widespread concern over food scarcity has surfaced because rural families are reportedly spending their savings to provide for displaced children. ${ }^{14}$ A recent survey conducted in one rural area after the earthquake found that individual families are taking in an average of five earthquake victims. ${ }^{15}$ Such additional stressors may heighten violence and abuse against women and children within these rural households.

Sex trafficking is likely to be a critical threat to vulnerable children, particularly girls, in the aftermath of this disaster. Both familial violence and economic insecurity are conditions that traffickers tend to manipulate to their advantage when coercing or luring young girls into precarious situations, such as sexual exploitation. ${ }^{16}$ Reports of rape of young women in Haiti's earthquake refugee camps have already spread. ${ }^{17}$ These precarious situations place girls at risk of HIV infection, additional sexual and physical violence, mental trauma and poor reproductive outcomes, including unwanted pregnancy. ${ }^{18}$

Aside from experiencing lack of public order, population displacement and increased economic insecurity, vulnerable children in Haiti may also be abandoned or neglected if HIVpositive family members who are their caregivers experience delays in recovery from earthquake-related injuries or develop comorbid conditions prevalent after earthquakes (e.g., asthma or posttraumatic stress disorder).

As the global community continues to work to rebuild Haiti, our findings highlight the importance of integrating a holistic approach to the well-being of children in a country where these issues have long been a problem. We echo comments by Aaron Greenberg, UNICEF's head of child protection, who recently said, "The amount of money that pours into a small country like Haiti, postcrisis, can be channeled to issues that existed precrisis." 19 On Mar. 31, 2010, the international donor community met at the UN in New York and committed nearly \$4 billion to Haiti. Nongovernmental coalitions and global agencies called for explicit address of issues related to violence against and safety of women and children.

\section{Next steps}

Given the international groundswell of support for postdisaster reconstruction in Haiti, strategies must be developed to ensure the safety and long-term well-being of children, with particular attention to gender-specific issues. A central goal must be to trace and reunify children with their families to the maximum extent possible.

It is essential that HIV-positive family members receive appropriate health care to reduce the likelihood of abandonment and neglect of children. Families who relocate to rural regions must be able to continue their treatment regimens. Addressing such issues may reduce children's risk of losing their HIV-affected caregivers.

It is also critical to consider children's safety within their caregiver networks. Although much attention after the earthquake has focused on child safety within the context of trafficking and related violence and exploitation from strangers, our findings showcase the high levels of violence against intimate partners encountered by Haiti's vulnerable children 
within their own households. Violence against female intimate partners is often underemphasized during rebuilding. Considering the harmful effects of exposure to such violence on the well-being of children, and the threat of increasing violence within families postdisaster, we emphasize the importance of integrating household safety assessments into postdisaster efforts.

Very few resources in Haiti exist to care for children who are forced to endure violence in their homes. As part of rebuilding efforts, infrastructure must be developed to address the safety of children. In response to fears of child trafficking, child protection hotlines have been established. Additional creative solutions must be developed to address both child trafficking and family violence, because many of the most vulnerable children in such circumstances may not have access to telephones. Again, this would require a more comprehensive approach to address gender-based violence.

Women must be offered protection as part of an effort to create safe and nurturing environments for children. Rebuilding efforts should include bolstering legal protection, increasing women's social and economic opportunities, and integrating violence-related services (e.g., counselling and screening) into health programming. Such initiatives will be most successful if Haitian women and children are given a voice in the rebuilding process. In addition, outreach to men and boys is critically needed in the form of programs aimed at preventing men's violence against women, because boys who are exposed to violence against intimate partners in the family are at risk of becoming perpetrators later in life. ${ }^{7}$ Such initiatives should be integrated into efforts for promoting psychosocial health, which continue to be urgently needed.

By developing optimal strategies that focus on promoting caregiver health and reducing violence against women, there is enormous potential to mitigate the health and safetyrelated aftershocks that threaten the well-being of Haiti's vulnerable children.

\section{This article has been peer reviewed.}

Competing interests: Funding from the Eunice Kennedy Shriver National Institute of Child Health and Human Development (L40 HD056848-01) provided support to Dr. Gupta for work on this article. Dr. Gupta served as Assistant Director of the Women's Health Program at Hopital Albert Schweitzer Haiti in Deschapelles, Haiti 2003/04. Dr. Agrawal was supported by award number T32MH020031 from the National Institute of Mental Health for work on this project. The content is solely the responsibility of the authors and does not necessarily represent the official views of the National Institute of Mental Health, the National Institutes of Health or the Hopital Albert Schweitzer Haiti.
Contributors: Dr. Gupta conceptualized the article, oversaw all data analyses, and led the interpretation of findings and writing of the article. Dr. Agrawal participated in conceptualizing the article, led all data analyses, and contributed to the interpretation of findings and writing of the article. Both authors revised the article for intellectual content and approved the final version submitted for publication.

\section{REFERENCES}

1. United Nations. Convention on the rights of the child. Geneva $(\mathrm{CH})$ : The Office of the United Nations High Commissioner for Human Rights; 1989.

2. At a glance: Haiti. UNICEF; 2010. Available: www.unicef.org/infobycountry/haiti _statistics.html\#66 (accessed 2010 Mar. 20).

3. 2009 World Factbook: Haiti. Washington (DC): Central Intelligence Agency; 2010. Available: www.cia.gov/library/publications/the-world-factbook/geos/ha html (accessed 2010 June 17)

4. Cayemittes M, Florence MF, Mariko S, et al. Enquête mortalité, morbidité et utilisation des services, Haïti, 2005-2006. Calverton (MD): Ministère de la Santé Publique et de la Population, Institut Haitien de l'Enfance et Macro International; 2007.

5. Guide to montoring and evaluation of the national response for children orphaned and make vulnerable by HIV/AIDS. New York (NY): UNICEF; 2005.

6. Pierre YF, Smucker GR, Tardieu JF. Lost childhoods in Haiti: quantifying child trafficking, restaveks, and victims of violence. Washington (DC): Pan American Development Foundation and Port-au-Prince (Haiti): US Agency for International Development/Haiti Mission; 2009. Available: www.itooamhaiti.org/ht/a/get documentaction/i/13583 (accessed 2010 Feb. 15).

7. World Health Organization. World report on health and violence. Geneva $(\mathrm{CH})$ : The Organization; 2002.

8. Silverman JG, Decker MR, Gupta J, et al. Maternal experiences of intimate partner violence and child morbidity in Bangladesh: evidence from a national Bangladeshi sample. Arch Pediatr Adolesc Med 2009;163:700-5.

9. Bancroft L, Silverman JG. The batterer as parent: assessing the impact of domestic violence on family dynamics. Thousand Oaks (CA): Sage; 2002.

10. Ross SM. Risk of physical abuse to children of spouse abusing parents. Child Abuse Negl 1996;20:589-98.

11. Report on the global AIDS epidemic. Geneva (CH): UNAIDS; 2008. Available: www.unaids.org/en/KnowledgeCentre/HIVData/GlobalReport/2008/2008_Global report.asp (accessed 2010 Feb. 15).

12. Anastario M, Shehab N, Lawry L. Increased gender-based violence among women internally displaced in Mississippi 2 years post-Hurricane Katrina. Disaster Med Public Health Prep 2009;3:18-26.

13. Hynes M, Robertson K, Ward J, et al. A determination of the prevalence of genderbased violence among conflict-affected populations in East Timor. Disasters 2004;28:294-321.

14. Food and Agricultural Organization and Care. Food crisis looms in rural Haiti. Atlanta (GA): CARE; 2010. Available: www.care.org/newsroom/articles/2010 102/Haiti-CARE-FAO-food-shortage-20100217.asp (accessed 2010 Mar. 20).

15. Sontag D. Rural Haiti struggles to absorb displaced. New York Times 2010 Mar. 16; Sect. A4.

16. Silverman JG, Decker MR, Gupta J, et al. Experiences of sex trafficking victims in Mumbai, India. Int J Gynaecol Obstet 2007;97:221-6.

17. Faul M. Women, girls rape victims in Haiti quake aftermath. The Washington Post 2010 Mar. 16. Available: www.huffingtonpost.com/2010/03/16/rape-in-haiti -women-girls_n_501588.html (accessed 2010 July 15).

18. Gupta J, Raj A, Decker MR, et al. HIV vulnerabilities of sex-trafficked Indian women and girls. Int J Gynaecol Obstet 2009;107:30-4.

19. Glasse J. Haiti's children still face problems. VOA News 2010 Mar 30. Available: www1.voanews.com/english/news/americas/Haitis-Children-Still-Face-Problems -89523372.html (accessed 2010 Apr. 1).

Correspondence to: Dr. Jhumka Gupta, Yale School of Public

Health and Center for Interdisciplinary Research on AIDS, Yale

University, 60 College St., Suite 400, New Haven CT 06510;

jhumka.gupta@yale.edu 